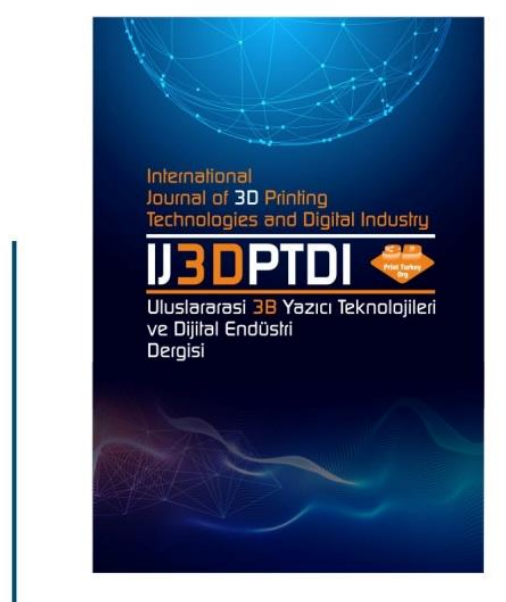

ULUSLARARASI 3B YAZICI TEKNOLOJILERI

VE DIJITAL ENDÜSTRI DERGISI

INTERNATIONAL JOURNAL QF 30 PRINTING TECHNOLOGIES AND DIGITAL INDUSTRY

I55N:2602-3350 [Online]

URL: https://dergipark.org.tr/ij3dptdi

\title{
TOPOLOGY OPTIMIZATION OF MOBILE TRANSPORTATION ROBOT
}

Yazarlar (Authors): Neslihan Demir®, H. Saygin Sucuoglu@, Ismail Bogrekci®, Pinar Demircioglu (iD*

Bu makaleye şu şekilde atıfta bulunabilirsiniz (To cite to this article): Demir N., Sucuoglu H.S., Bogrekci I., Demircioglu P."Topology Optimization of Mobile Transportation Robot" Int. J. of 3D Printing Tech. Dig. Ind., 5(2): 210-219, (2021). 


\title{
TOPOLOGY OPTIMIZATION OF MOBILE TRANSPORTATION ROBOT
}

\author{
Neslihan Demir a,b iD, H. Saygin Sucuoglu a iD, Ismail Bogrekci a iD, Pinar Demircioglu a iD* \\ a Aydin Adnan Menderes University, Faculty of Engineering, Mechanical Engineering Department, TURKEY \\ ${ }^{\mathrm{b}}$ PhD Student of YOK 100-2000 on Robotic Technologies, TURKEY \\ *Corresponding Author: pinar.demircioglu@adu.edu.tr
}

(Received: 08.06.2021; Revised: 28.06.2021; Accepted: 09.08.2021)

\begin{abstract}
The main aim of this study was to decrease the weight of mobile transportation robot and to check the optimized shape using topology optimization and structural analysis. The analyses were applied using CAE (Computer Aided Engineering) Software with the methods of topology optimization and structural analysis. In the topology optimization process, the preserved areas were defined for connection and fixing areas. The aim was to decrease the weight of robot structure and lower the energy consumption of the robotic system. After topology optimization, the structural strength analysis was applied to the new optimized structure to check about the strength. The weight of the structure was decreased with the ratio of $20 \%$. In addition to this, the structural strength of the robot was observed similar to the original body with the factor of safety value as three.
\end{abstract}

Keywords: Mobile Robot. Robotic Arm. Structural Analysis. Topology Optimization. Weight Reduction.

\section{INTRODUCTION}

Manufacturing technologies have been evolving with Industry 4.0 during the recent years. These technologies have offered new advanced manufacturing approaches. Manufacturing techniques have become easier, faster, more effective, and more high performance with less cost, time, and effort with these approaches. Additive manufacturing is one of advanced manufacturing approaches. Additive manufacturing is defined as a process of joining materials to make parts from 3D model data, usually layer upon layer, as opposed to subtractive manufacturing and formative manufacturing methodologies by ISO/ASTM [1]. It has called with different terms such as Rapid Prototyping, 3D printing, Layered Manufacturing [2]. The parts can be manufactured with complicated and difficult geometry [3]. In design process, it is more functional and practical comparing with the conventional manufacturing techniques and thus more attractive for design engineers. Especially while seeking the optimum design, additive manufacturing has assigned to manufacture the topological optimized design. So that topology optimization has been a functional technique in order to improve design while optimizing shape of parts with additive manufacturing techniques [4].

Robotic technologies have been transforming in every aspect of engineering application. Recently, efforts have focused on automation of robotic systems in terms of unmanned functions and operations at the industrial environment. There is no doubt that Industry 4.0 has a significant role on development of unprecedented robotic applications. The innovative studies have been managed to study on Autonomous Mobile Robot. Thus, considering the requirements at the manufacturing facilities, an autonomous mobile robot was developed for transportation semi-finished products, parts, tools with specific dimensions between operation units and warehouse in manufacturing plant.

It is possible to find studies of Autonomous Mobile Robot in academic and commercial field focused on particularly material transportation in manufacturing facilities. These studies have been conducted in the numerous aspects of operation for material picking and placing in industrial environments. KUKA 
Robotic Corporation and Amazon Robotics are the most recognized and preferred Mobile Robot brands in material handling and transportation for industrial purposes [5] [6]. There are numerous academic studies on Mobile Robots for picking and placing in manufacturing facilities such as Jang et. al. [7] developed an algorithm about self-collision avoidance of a mobile manipulator, Sholbach et. al. [8] studied especially on arm characteristics of Mobile Robot, likewise Widhiada et. al. [9] focused on PID control of Mobile Robot, Paakönen [10] published a Master Thesis on Cloud-based Remote Control of Autonomous Mobile Robots in industrial environments, Oltean [11] conducted a study on low-cost Mobile Robot Platform, Sichkar et. al. [12] proposed a solution for stabilization of Mobile Robots in transportation of goods, Lee et. al. [13] explored an approach for minimizing deliver time between picking and placing materials and optimizing the Mobile Robot routing issue.

The main objective of Mobile Transportation Robot is to pick, carry and place desired parts to operation units and warehouse. Mobile Transportation Robot was designed using a parametric solid modelling technique on SolidWorks 2021 as a computer aided design (CAD) program. Mainly, mobile transportation robot consists of two modules, mecanum wheeled locomotion module and robotic arm module, respectively.

In the recent years, it has been presented numerous studies on topology optimization for mass reduction of mobile vehicles. Jagtap and Dhoke managed to decrease the mass of exhaust mounting bracket in the ratio of 50\% considering production constraints [14]. Topac et. al. performed topology optimization for a support bracket at the back shaft of truck and obtained 63\% of mass reduction [15]. Karaoglan et. al. conducted a study on determination of optimum profile thickness and reduction the mass according to areas where stress was low on the chassis using topology optimization and in the consequence of the study, they obtained \%18.81 mass reduction [16]. In this paper, it is aimed to optimize CAD design by topology optimization and reconstitute the design of Mobile Transportation Robot for rapid prototyping.

\section{MOBILE TRANSPORTATION ROBOT}

Mobile Transportation Robot was design using a parametric solid modelling technique on SolidWorks 2021 as a computer aided design (CAD) program. Mainly, mobile transportation robot consists of two modules, mecanum wheeled locomotion module and robotic arm module, respectively (Figure 1).

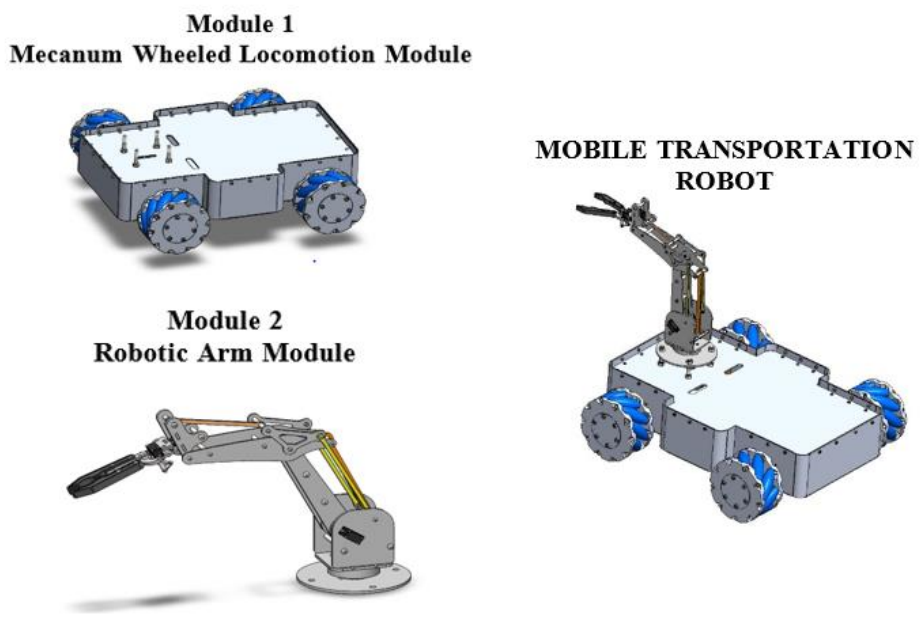

Figure 1. Modules of Mobile Transportation Robot

- Mecanum wheeled locomotion module was designed for performing motion consisting of forward, backward, skipping \& sliding on the ground. This module comprises mecanum wheels, required equipment ensuring mobility, chassis etc. All links have been implemented for locomotion to provide mobility, maneuverability.

- Robotic arm module enables to grip, move and leave desired parts, equipment etc. on the below of the chassis. All links have been implemented for manipulation to provide manipulability as pick and place with robotic arm. 
Mecanum wheeled locomotion module can be applied for mobility while at the same time robotic arm module can be applied for manipulation in order to perform various tasks. The mecanum wheeled locomotion module was designed to achieve objectives as performing motion consisting of forward, backward, skipping \& sliding on the ground of a manufacturing plant, carrying semi-finished products, parts, tools with specific dimensions (Figure 2). It is comprised of four mecanum wheels, required equipment ensuring mobility, chassis etc. All links have been implemented for locomotion to provide mobility and maneuverability.

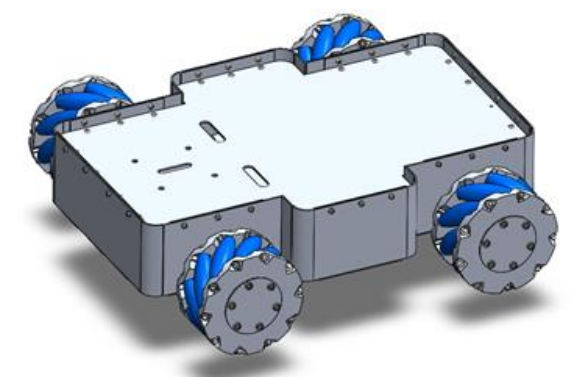

Figure 2. Mecanum Wheeled Locomotion Module of Mobile Transportation Robot.

The mobile robot is supposed to carry a maximum load of $30 \mathrm{~kg}$ as small semi-finished products, parts, tools between operation units and warehouse in an industrial environment. Thus, the maximum linear velocity is $2 \mathrm{~m} / \mathrm{s}$. The chassis of mobile robot was designed with dimensions $580 \mathrm{~mm}$ long and $400 \mathrm{~mm}$ wide considering the constraints on transportation of specific parts, environment condition, performing required objectives. The material of chassis would be aluminum 6061 sheet metal with $2 \mathrm{~mm}$ thickness. Four mecanum wheels were envisaged to use for mobility. The detailed dimensions of chassis are given in Table 1 and symbols of related dimensions are shown in Figure 3.
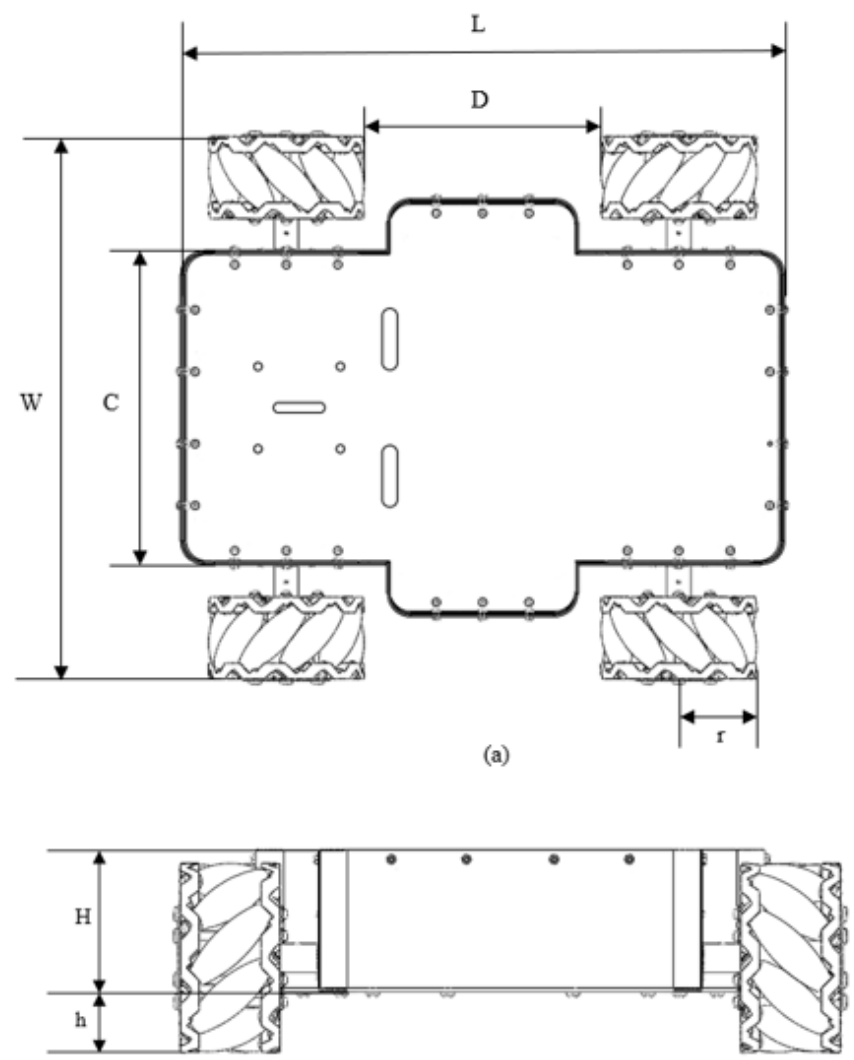

(b)

Figure 3. Dimensions of chassis with mecanum wheels (a) Top view (b) Front view. 
Table 1. Dimensions and explanation for platform chassis with mecanum wheels.

\begin{tabular}{ccc}
\hline \hline Symbol & Value (mm) & Explanation \\
\hline \hline $\mathbf{L}$ & 580 & Chassis Length \\
$\mathbf{W}$ & 400 & Chassis Width \\
$\mathbf{C}$ & 300 & Vertical Distance Between Right \& Left Wheel \\
$\mathbf{D}$ & 230 & Vertical Distance Between Front \& Back Wheel \\
$\mathbf{r}$ & 75 & Radius of Wheel \\
$\mathbf{H}$ & 113 & Chassis Height \\
$\mathbf{h}$ & 50 & Ground Clearance of Chassis \\
\hline \hline
\end{tabular}

\section{TOPOLOGY OPTIMIZATION}

Advanced manufacturing technologies have been contributing a great number of benefits such as lowering time, cost, and effort, gaining high efficiency and performance etc. for industrial institutions. Apart from all these, new approaches have been sought for developing optimal solutions for manufacturing process including design process. Topology optimization is an effective method for getting optimal structure of a product during the design process. It is accepted that topology optimization is the most comprehensive technique due to provide new design ideas without an aforethought design for engineers and designers [17].

Generally, it is described that the structural optimization comprises of sizing, shape, and topology optimizations [18]. Sizing optimization is to get convenient cross-sectional area of each element for optimal form and alter the dimensions of the structure. Shape optimization is to optimize exterior of the shape without changing connections of the structure. Topology optimization is to define how to make optimal connections of components for the structure [19]. Topology optimization can be defined as to optimize the material distribution in order to acquire an ideal structure [20]. The structural optimization techniques are presented in Figure 4.

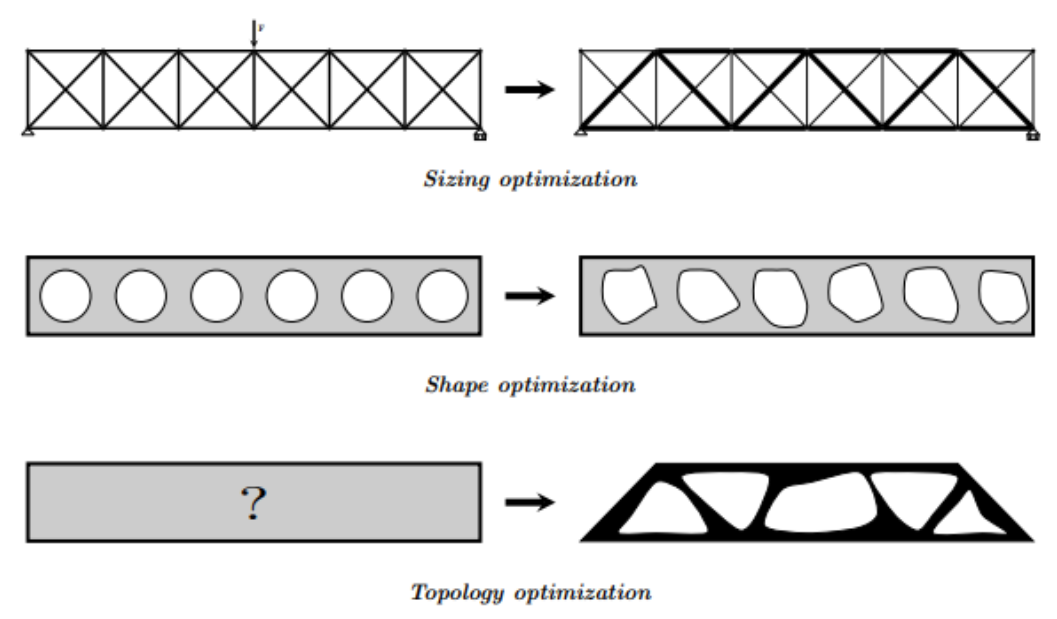

Figure 4. Illustration of sizing, shape and topology optimization [21].

The areas, which have been determined to affect the stress, deformation, mass, and natural frequency of the structure, are defined to remove from the structure in the topology optimization [22]. It is fulfilled creating and erasing elements, holes, bulges, and grooves of the structure during the material distribution process with topology optimization technique [23]. Thereby it is reached an ideal structure while reducing the mass without changing the function of part.

At the topology optimization process, the design area of actual 3D solid model is determined to optimize. Then the required constraints are identified on the 3D solid model and apply the force. The obtained new 3D solid model is analyzed, and the process can be repeated in case of not getting the required results, after the topology optimization has been completed [24] [25]. 


\subsection{Topology Optimization of Mobile Transportation Robot}

In this study, topology optimization was conducted for chassis Mecanum Wheeled Locomotion Module in terms of mass target. The process was started with considering target part of predesigned chassis for topology optimization module on ANSYS Workbench. For enabling topology optimization easier, structural constraints were found with Static Structural Module on ANSYS Workbench. Thus, it was determined identification of load forces and exposed areas to forces on target part. The displacement, stress, and safety factor were obtained from Static Structural analysis, according to $300 \mathrm{~N}$ load force.

The chassis of Mobile Transportation Robot was designed to fulfill mobility and carrying tasks. In consideration of carrying tasks, the chassis was analyzed on topology optimization. The target part was opted as the top part of the chassis for topology optimization, therefore in the chassis design, the top part was the main carrier of loads as small semi-finished products, parts, tools and robotic arm module. It is presented in Figure 5. The design was planned and performed considering that material of top part would be Aluminum $6061 \mathrm{O}$ sheet metal with $2 \mathrm{~mm}$ thickness. Mechanical properties are presented in Table 2 for this material.

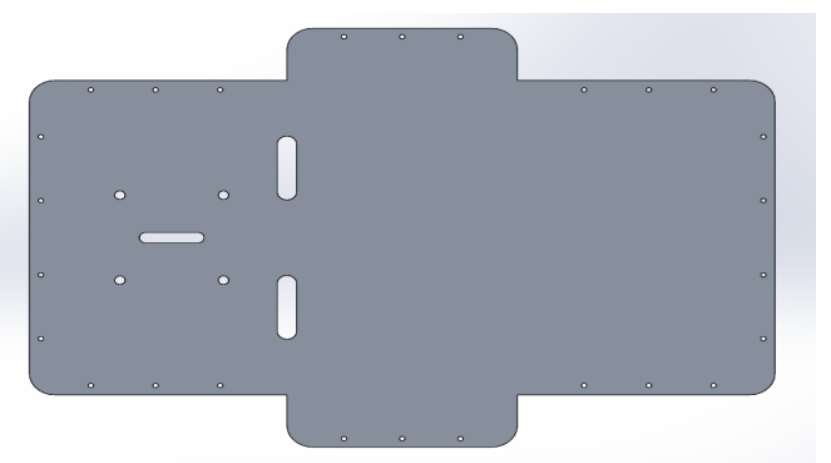

Figure 5. Top part of Mobile Transportation Robot chassis

Table 2. Mechanical properties of Aluminum 6061 O sheet metal [26].

\begin{tabular}{cc}
\hline \hline Property & Value (Metric) \\
\hline \hline Density & $2.70 \mathrm{~g} / \mathrm{cm}^{3}$ \\
Young Modulus & $68.9 \mathrm{GPa}$ \\
Shear Modulus & $26 \mathrm{GPa}$ \\
Yield Strength & $276 \mathrm{MPa}$ \\
Ultimate Tensile Strength & $310 \mathrm{MPa}$ \\
Shear Strength & $207 \mathrm{MPa}$ \\
Fatigue Strength & $96.5 \mathrm{MPa}$ \\
\hline \hline
\end{tabular}

Topology optimization was conducted on ANSYS 2021R1 Workbench via using Static Structural and Topology Optimization Modules. The solid model of the top part was analyzed to determine mechanical behavior under a specific load. It was accepted that applied force would be $300 \mathrm{~N}$ below top part of the chassis. Thus, at the first step Static structural analysis was composed of 552,873 nodes with 99,686 elements. The element order was quadratic and average element size was $2 \mathrm{~mm}$. It was assumed that the maximum applied load was enforced on the top part of the chassis, therefore the top part of chassis was taken into consideration. The applied force on the top part was accepted as $300 \mathrm{~N}$.

According to static structural analysis, it was determined 51,199 MPa as maximum equivalent stress and $0.0997 \mathrm{~mm}$ as total deformation, when $300 \mathrm{~N}$ was applied on the top part of chassis. Also, the safety factor was found as 4.883. They are demonstrated in Figures 6, 7 and 8. 


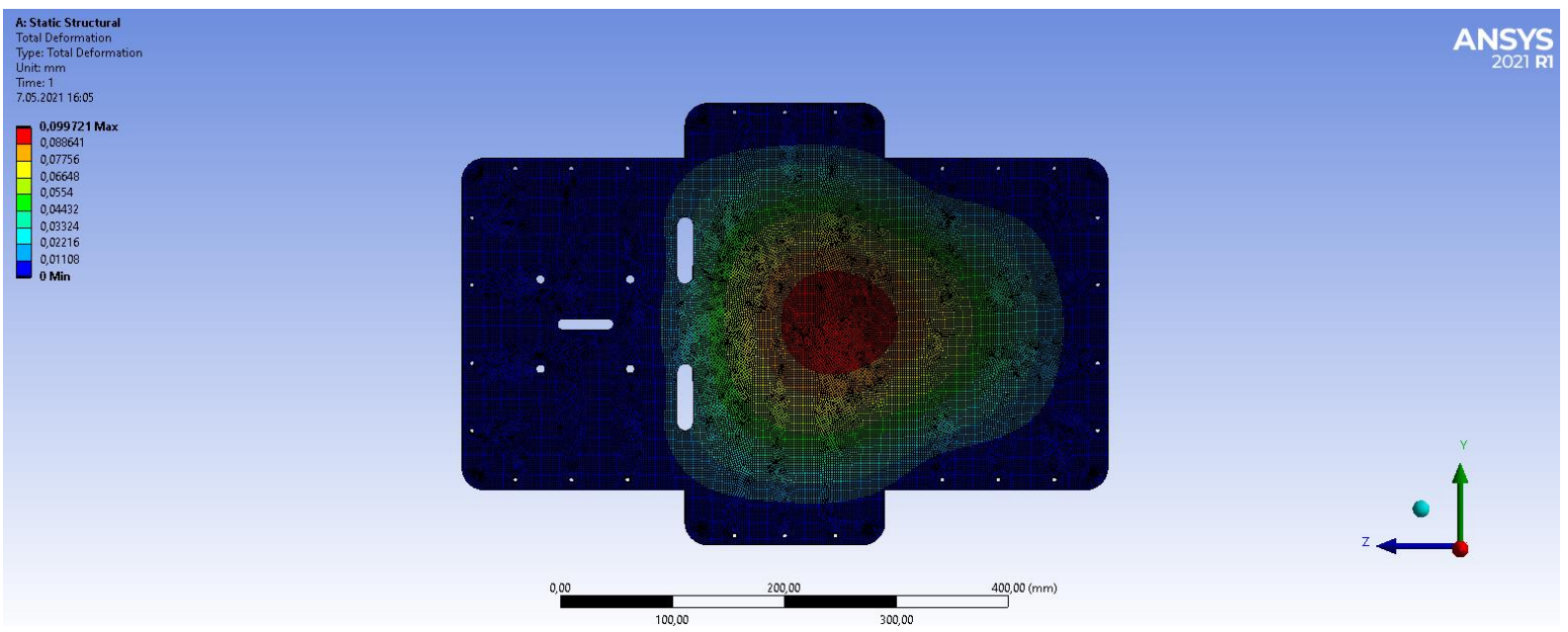

Figure 6. Total deformation according to static structural analysis before topology optimization.

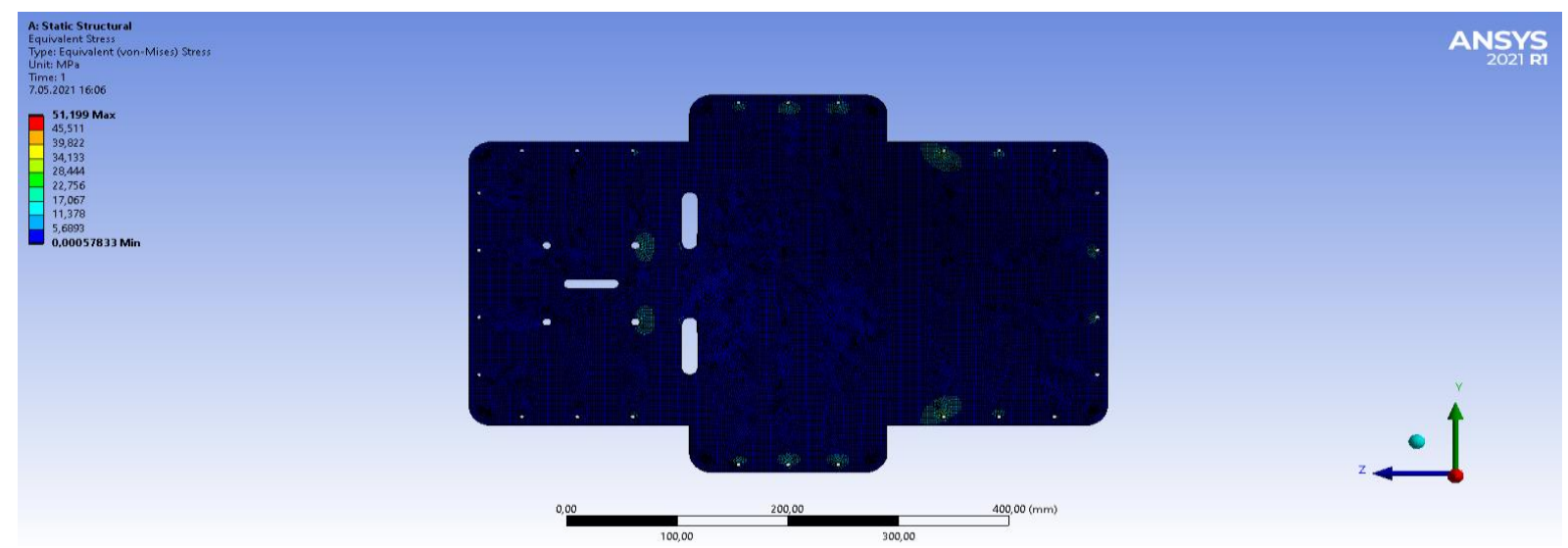

Figure 7. Equivalent stress according to static structural analysis before topology optimization.

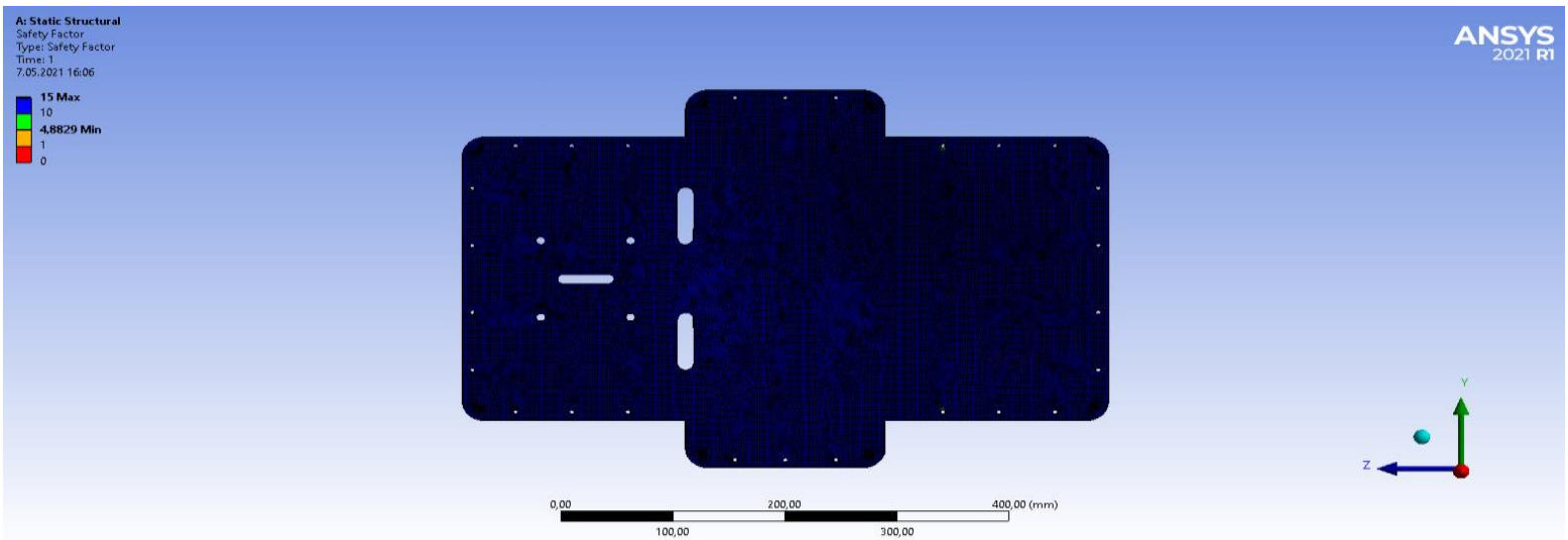

Figure 8. Safety factor according to static structural analysis before topology optimization.

After structural analysis, parameters as deformation and stress were taken into account for topology analysis. Ansys Workbench has an easy way to connect parameters between Static Structural Module and topology Optimization Module. Analysis settings of topology optimization were cautiously conducted. Solver type was opted as Sequential convex programming and sequential convex programming (SCP) is described as a local optimization method for nonconvex problems that leverages convex optimization [27]. Connection areas were selected as exclusion region. The objective was to minimize the mass of top part on the static structural environment by using the optimization type as topology optimization density based. The constraint was accepted approximately $80 \%$ of mass. The total mass of top part was $4.34 \mathrm{~kg}$ and after topology optimization, the optimized mass was obtained as 3.56 
$\mathrm{kg}$ by minimizing in the proportion of approximately $80 \%$. The optimized shape of top part is presented in Figure 9 on topology optimization module of Ansys Workbench.

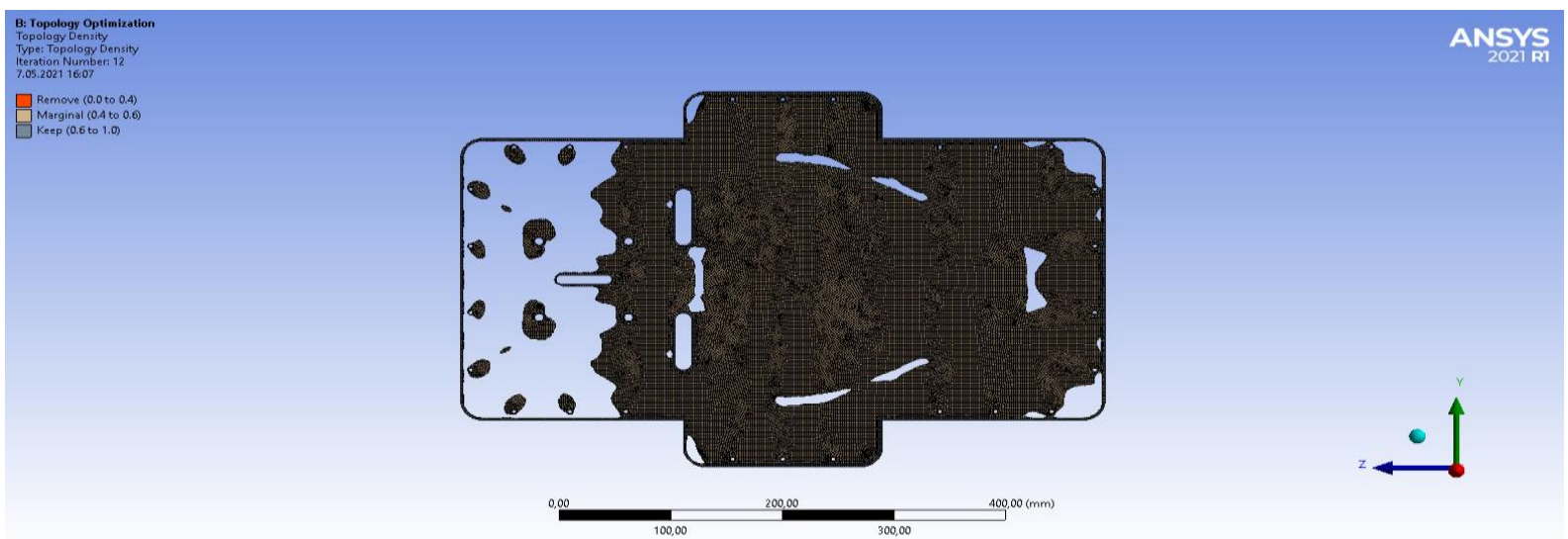

Figure 9. Optimized top part of chassis in the percentage of 80 .

As is seen from Figure 9, shape was not convenient to use functionally as design and manufacturing. Therefore, a new designed was enhanced as in Figure 10, in regard of holding the optimized mass and generally optimized shape.

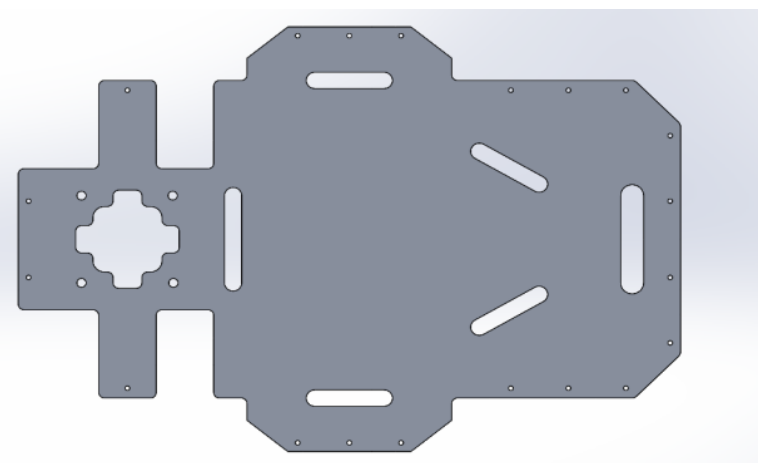

Figure 10. Design of top part after topology optimization.

For verification of the new design, static structural analysis was conducted on optimized top part in the same conditions. Analysis was composed of 453,617 nodes with 81,226 elements. It was determined $48,565 \mathrm{MPa}$ as maximum equivalent stress and $0.365 \mathrm{~mm}$ as total deformation, when $300 \mathrm{~N}$ was applied on the top part of chassis. Also, the safety factor was found as 5.683. They are demonstrated in Figures 11,12 and 13.

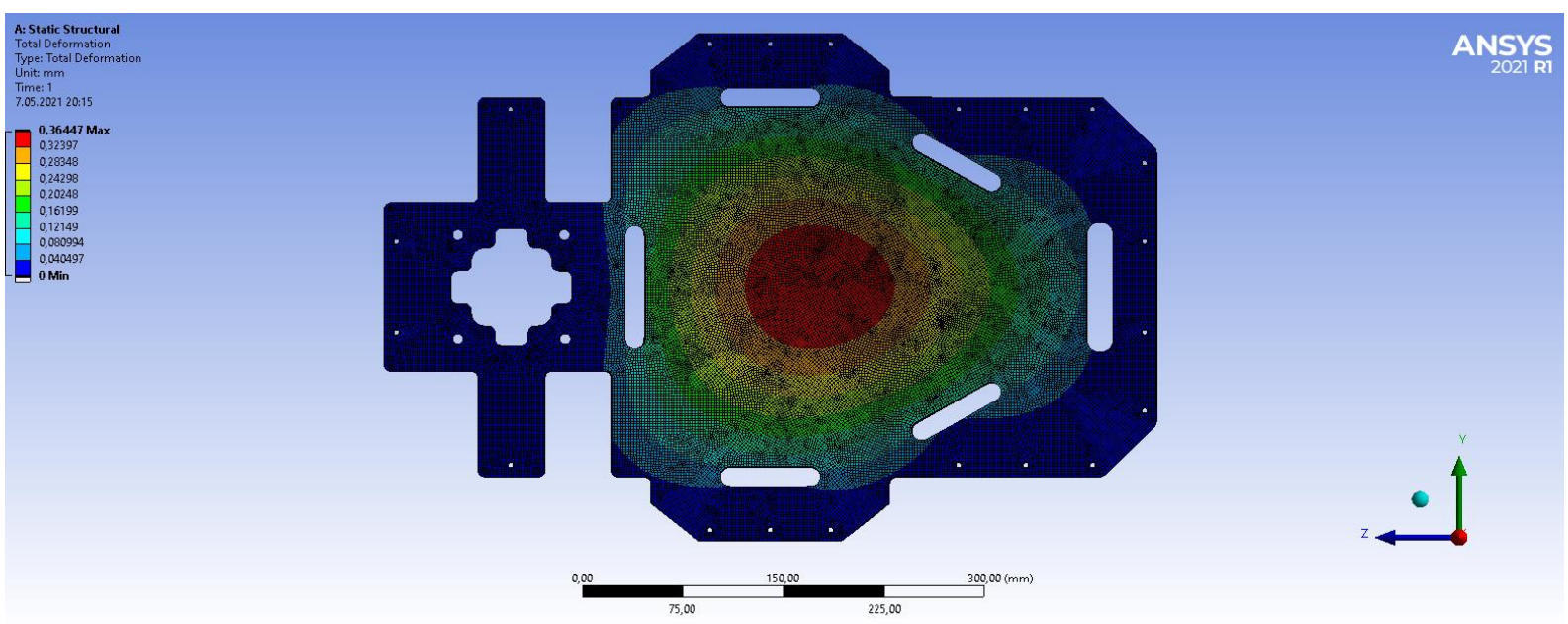

Figure 11. Total deformation of optimized top part after topology optimization 


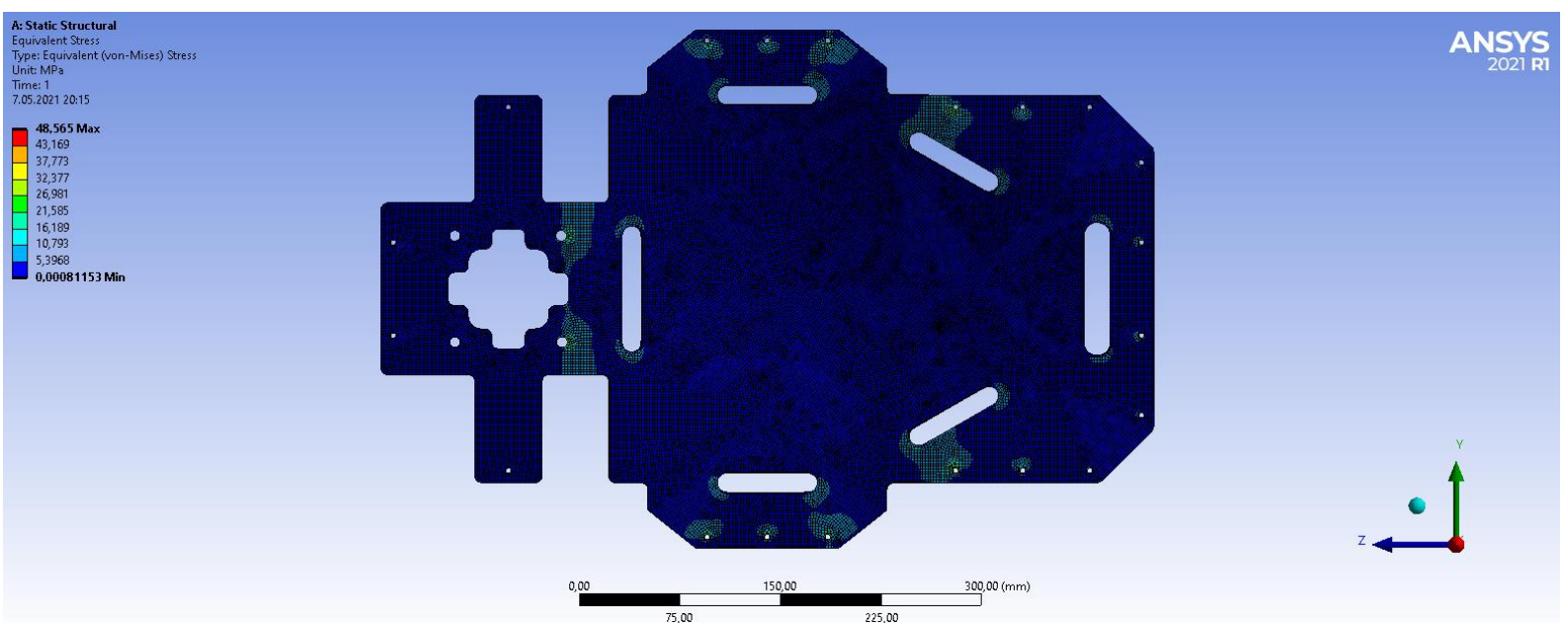

Figure 12. Equivalent stress of optimized top part after topology optimization.

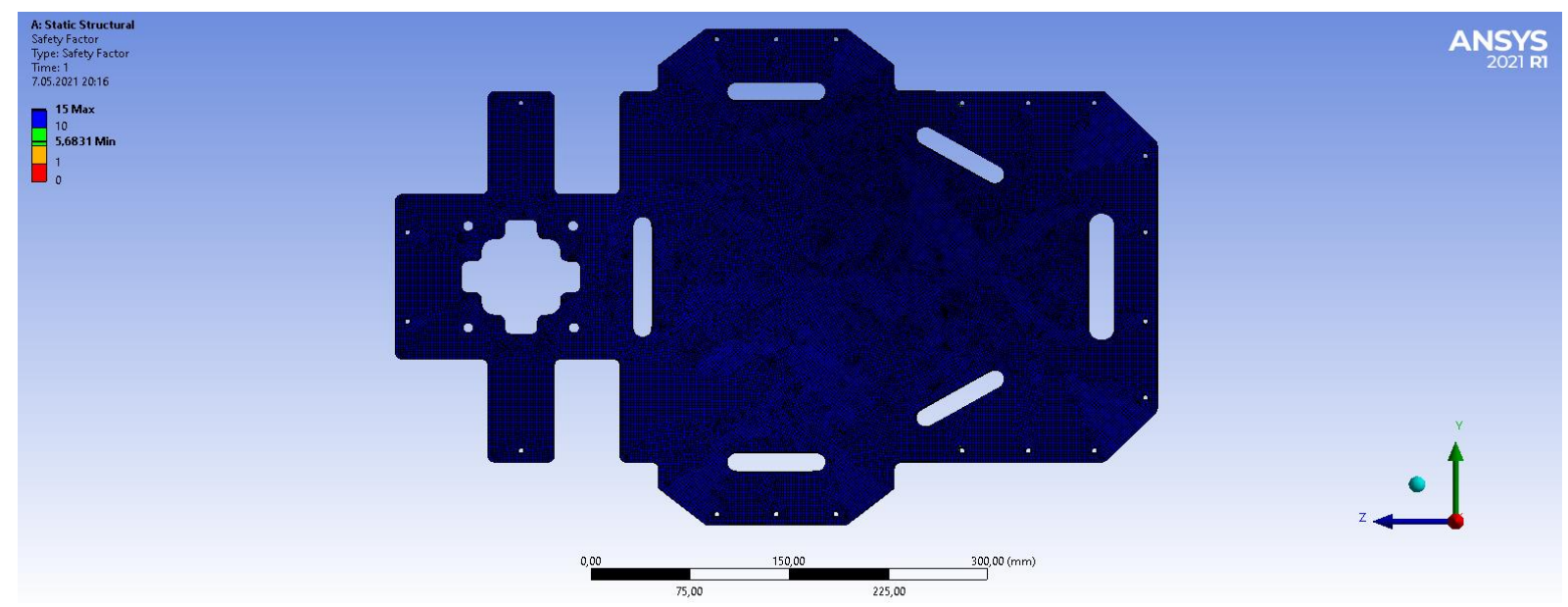

Figure 13. Safety factor of optimized top part after topology optimization.

\section{CONCLUSION}

In this study, topology optimization and structural analyses were applied to the mobile transportation robot to decrease the weight and to check the strength of the robot. The topology optimization was applied in order to decrease weight $20 \%$. Structural analyses were applied to the original robot body and optimized shape. Obtained results from analyses environments were compared. The occurred stress values were observed too close to each other with the values about 51 and $48 \mathrm{MPa}$. The factor of safety values was also found close to each other with the values of 4.8 and 5.7, respectively.

Karaoğlan et al. applied a topology optimization procedure to truck chassis and decrease the weight of the chassis successfully by decreasing the weight with the value of $18.81 \%$ [16]. In our study the topology optimization was applied to the robotic carrier chassis and the weight was decreased with the value of $20 \%$. From these results it can be concluded that the topology optimization process was applied successfully. The weight was decreased $20 \%$, almost same occurred stresses and factor of safety values were obtained.

\section{REFERENCES}

1. ASTM. "Standard terminology for additive manufacturing-general principles. Part 1: Terminology" ISO/ASTM Stand. 52792, ASTM. 2015. 
2. Bandyopadhyay, A., Bose, S. “Additive Manufacturing, Second Edition” CRC Press Taylor \& Francis Group, 2020.

3. Gibson, I., Rosen, D., Stucker, B., Khorasani, M. "Additive Manufacturing Technologies Third Edition” Springer, 2021.

4. Aktimur, B., Gökpınar, E. “Katmanlı Üretimin Havacılıktaki Uygulamaları”, Gazi Üniversitesi Fen Bilimleri Dergisi Part C: Tasarım ve Teknoloji, Vol. 3, Pages. 463-469, 2014.

5. Kuka Robotics, https://www.kuka.com/, April 10, 2020.

6. Amazon Robotics, https://www.amazonrobotics.com/, April 10, 2020.

7. Jang, K., Kim, S., Park, J. "Reactive Self-Collision Avoidance for a Differentially Driven Mobile Manipulator", Sensors, Vol. 21, Issue 3, Pages 890-911, 2021.

8. Sohlbach, L., Erchen, S., Schmidt, K. "Development of a 5 DOF manipulator for a mobile robot" $202021^{\text {st }}$ International Conference on Research and Education in Mechatronics (REM). Cracow, Poland, 2020.

9. Widhiada, W., Snthiarsa, I. G. N., Partha, C. G. I. "Design of Motion Control for Mobile Robot Manipulator", International Journal of Mechanical Engineering and Robotics Research, Vol. 9, Issue 11, Pages 1509-1514, 2020.

10. Paakkonen, R. "Cloud-based Remote Control of Autonomous Mobile Robots in Industrial Environments", Master Thesis, Aalto University School of Electrical Engineering, Helsinki, Finland, 2020.

11. Oltean, S. E. "Mobile Robot Platform with Arduino Uno and Raspberry Pi for Autonomous Navigation", Procedia Manufacturing, Vol. 32, Pages 572-577, 2019.

12. Sichkar, D. P., Bezumnov, N., Voronov, V. I., Voronova, L. I., Dankovtsev, V. I. "Moving Elements of Mobile Robots Stabilization Modelling”, Systems of Signals Generating and Processing in the Field of onBoard Communications, Moscow, Russia, 2019.

13. Lee, H. Y., Murray, C. C. "Robotics in order picking: evaluating warehouse layouts for pick, place, and transport vehicle routing systems", International Journal of Production Research, Vol. 27, Issue 18, Pages 5821-5841, 2018.

14. Jagtap, M., Dhoke, A. “Topology optimization of exhaust mounting bracket.” In Tech Mahindra, Altair Technology Conference, India, 2017.

15. Topaç, M. M., Karaca, M., Aksoy, B., Deryal, U., Bilal, L. "Lightweight design of a rear axle connection bracket for a heavy commercial vehicle by using topology optimisation: A case study.", Mechanics, Vol. 26, Issue 1, Pages 64 72, 2020.

16. Karaoglan, M. U., Turnalı, O. Y., Kuralay, S. N. "Hafif hizmet aracı şasi analizi ve optimizasyonu.", Dokuz Eylul Universitesi Mühendislik Fakültesi Fen ve Mühendislik Dergisi, Vol. 18, Issue 54, Pages 502-512, 2016.

17. Liu S, Li Q, Junhuan Liu, Chen W, Zhang Y. A "Realization Method for Transforming a Topology Optimization Design into Additive Manufacturing Structures”, Engineering, Vol. 4, Pages 277-285, 2018.

18. Eren, O., Sezer, H. K. "Üretken Tasarım ve Topoloji Optimizasyonu Yaklaşımlarıyla Ürün Tasarımı" Uluslararası Bilim, Teknoloji ve Sosyal Bilimlerde Güncel Gelişmeler Sempozyumu, Ankara, 2019.

19. Christensen P, Anders K., “An Introduction to Structural Optimization” Springer, 2009.

20. Thummar, D R. "Truss Topology Optimization Using Modified Genetic Algorithm, Master of Technology in Machine Design" Master Thesis, Department of Mechanical Engineering School of Engineering, RK University, Rajkot, Gujarat, 2014. 
21. Issa, M. V. “On the Accuracy and Efficiency of Cross-Entropy Method for Structural Optimization”, Master Thesis, State University of Rio de Janeiro Centro de Science and Technology Center, Rio de Janeiro, Brazil, 2019.

22. Nadir W, Kim Y, Weck O. L. "Structural Shape Optimization Considering Both Performance and Manufacturing Cost” 10th AIAA/ISSMO Multidisciplinary Analysis and Optimization Conference, Albany, Newyork, 2004.

23. Saleem W, Yuqing F, Yunqiao W. "Application of Topology Optimization and Manufacturing Simulations - A new trend in design of Aircraft components" Proceedings of the International Multiconference of Engineers and Computer Scientists 2008 Vol II IMECS, Hong Kong, 2008.

24. Top, N., Şahin, I., Gökçe, H. “3B Yazıcı Teknolojisi için Topoloji Optimizasyonu: Otomotivde Salıncak Kolu Üzerine bir Çalışma" Third International Symposium on Industrial Design \& Engineering (ISIDE), Antalya, 2018.

25. Sahin, I. "Mühimmat Sistemlerinde Kullanılan Askı Kancalarında Geometri Tabanlı Topoloji Optimizasyonu” Third International Symposium on Industrial Design \& Engineering (ISIDE), Antalya, 2018.

26. Cavallo, C. "All About 6061 Aluminum (Properties, Strength and Uses)", https://www.thomasnet.com/articles/metals-metal-products/6061-aluminum/, May 04, 2021.

27. Duchi, J. "Sequential Convex Programming", https://stanford.edu/class/ee364b/lectures/seq notes.pdf, May 04, 2021. 